\title{
THE STUDY OF MATERIAL CULTURE
}

\section{The study of material culture}

Since the beginning of the twenty-first century there has been in the social sciences a renewed interest in the theorization and study of material culture. After several decades of thinking centered on persons, more attention is now being given to things, as they are seen as important, and active, constituents of social life. This interest is by no means new. In the nineteenth century European collectors already studied systematically ancient and exotic objects, and this resulted in the creation of the theoretical basis of archaeology. The current examination of material culture, nevertheless, focuses on new questions such as if objects have agency or if the definition of materiality is culturally determined. Also at present artifacts are considered important sources of information to study contexts previously approached through other media such as documents or architecture; for example, the new archeological studies of colonialism centered on material culture.

In the social sciences there have been various views on the significance of material culture in the study of society. These perceptions have mainly depended on how the relationship between subjects and objects, persons and things, humans and non-humans is understood. Webb Keane recognizes (2006:197) four basic perspectives in modern times: (a) a position focused on production, represented in particular by Marxist theory, which assumes that subjects in pre-capitalist societies realized themselves through transformation of nature into objects, while under capitalism objects are seen as external to subjects; (b) a position based on representation, mainly represented by the Structuralism of Durkheim and Mauss, in which objects are seen as reproductions of the worldview and social order of subjects; (c) a position based on development in which subjects develop as a result of encounters with objects, this is mainly represented by psychological approaches that emphasize the central role of objects in persons, as fetishes and providers of new sensory experiences, and (d) a position 
based on the extension of subjects through objects, mainly represented by Post-structuralist thinking in which objects are attributed with qualities of subjects, in particular with agency, and for this reason, they are able to realize and extend subjects.

At present this last view is becoming more common in social studies. Recent investigations are based on the assumption that material objects have characteristics of subjects, such as agency and complex intentionality (Hoskins 2006:74), and that things constitute rather than reflect social realities (e.g., Gosden 2006:437; Guarinello 2005:20; Keane 2006:199; Sofaer 2007:2; Tilley 2002:23). These thoughts have been the result of two influential works: Arjun Appadurai's collection of papers The Social Life of Things (1986) and Alfred Gell's Art and Agency (1998). The contributors to the Appadurai volume, at that time provocatively, looked at things as if they led social lives. By focusing on exchange and circulation, they explored the ways in which people find value in things, and things give value to social relations. In the same manner, Gell proposed that art is produced in order to influence thoughts and actions of people. Once a piece of art is created, it becomes agency because it produces effects on individuals. In this view it is believed that people and material culture maintain a dialectical relation, and therefore objects are able to influence actions of people, and can be active agents in creating social relations. This can be the case in colonial encounters as, for example, in early colonial Mesoamerica native potters were inspired by the new Spanish attires and began to produce figurines representing Spanish lords -with huts, beards, and Spanish haircut-, ladies -with long dresses, huts and children-, and animals -horses, donkeys, dogs- (Barlow 1990; Charlton et al. 2007:456-458; Otis Charlton 1995; von Winning 1988). These new stylistic attributes gave way to new functions and relations between persons and figurines, as they began to be incorporated in the Christian ritual in Crèche scenes that became popular in Europe by the mid-1500 (Charlton et al. 2005:62).

In addition, objects may have different roles and meanings in different social contexts (see Appadurai 1986). As Fred Myers (2001:6) argues, the value attributed to objects is movable and therefore problematic. That is, artifacts can be considered in some situations commodities while in others they are viewed as valuables. Following Thomas (1991:103), if the links between an object and its producers or former owners are erased, uninteresting or inconsequential, then it can be considered a commodity. In contrast, objects that have 
embedded stories about their sources, users and producers are valuables. Finely decorated ceramics, for example, can be in certain contexts valuables as they may be associated to particular past celebrations or to well-known producers. On the other hand, plain ceramics for daily uses are often only commodities. In some historical processes, however, the values, and roles, assigned to objects can be more complex and even incongruent. For example, in colonial South African Cape of Good Hope, coarse ware locally produced by European potters provoked a variety of responses, as it was part of the mechanisms to define and redefine identities of both colonizers and colonized (Jordan and Schrire 2002:265). In view of that, the relationship between material change and social change may be more complex than we have thought.

\section{Change in material culture}

Material change has not only been studied from different perspectives but also from different emotions. Some scholars have perceived material change as positive, as they have equated it to progress. George Foster (1962:5), for example, as an anthropologist working in several countries for development projects of the United States, assumed that in less industrialized places changes in technology and artifacts led to progress and to a better stardard of living. In his opinion, such progressive change was desirable to people everywhere. In contrast, other scholars have perceived material change as negative. As Victor Buchli (2002:8) explains, the rapid transformations consequence of industrialization provoked that changes in material culture were seen with nostalgia, as loss. Such melancholic perception of change has often contrasted with the ideas that producers and users of particular artifacts have about change. In Mesoamerica, for example, the present decline of ceramics for household purposes in favor of metal, porcelain and plastic artifacts is usually seen as improvement by their users, but as decay by archeologists. This shows that the argumentation around change, present welfare and cultural heritage is complex, and often made only from the standpoint of the researcher.

Material change, and its relation to social change, has been studied from different perspectives over the last fifty years. During the 1960s and 1970s, for example, a common model was that change occurred when a component of a particular social, economic or ecological 
system was altered, and such alteration could result in the modification of artifacts (e.g., Binford and Binford 1968; Flannery 1968). During the 1980s and 1990s this systemic thinking was replaced by models centered on the agency of people (e.g., Giddens 1979). That is, it was held that individuals take decisions that provoke changes, including material changes. In contrast, a more recent perspective suggests that material culture can be an agent of change. Gosden (2006:425), in a discussion of long-term change, argues that objects, especially in terms of their forms and styles, have a longer life than humans. In consequence, he explains, we learn crucially from things, not only from people. That is, we are taught by people how to make and use things, but we really learn from the form things take and from the manner in which they are made. Thus, for Gosden, objects may guide people to shape short-term processes and events. In this argument things, rather than being considered intermediaries or products of human ideas, are viewed as kind of autonomous entities. Producers of artifacts innovate because they learn new ideas from other people and because they have creative inspiration, but also because they are influenced by other artifacts that they want, or reject, to imitate. In this perspective the relationship between social and material change is seen as dialectical and complex.

Change is intrinsically related to conservatism. For this reason, many studies of material culture change have also considered material conservatism. The bipolar approach 'change and continuity' is widely extended in the analysis of past and present objects. This view, however, may be problematic for several reasons. It presupposes that change and continuity are processes independent of the perception of the observer. For example, an archeologist identifies changes in ceramics morphology while producers and users affirm that they are the same as in the past. Also, change and conservatism are viewed as polar oppositions, although examples of the material world show that there is often a continuum between both trends and it is not easy to find a division line. In addition, conservatism is habitually considered as lack of change, as a kind of static state. However, the conservative reproduction of culture is also a form of action, as Judith Farquhar (2006:154) argues in her analysis of food and eating cultures worldwide. This is particularly evident in colonial encounters in which native people choose to maintain their material culture in order to preserve elements of self-recognition and sources of thrust in the new colonial society. Furthermore, this bipolar perspective suggests that 
change, mainly of material culture, is monolithic. However, when artifacts, and their manufacturing technologies, are observed through long spans of time, it can be identified that they have various dimensions of change and conservatism, in addition to various perceptions of such dynamics of continuity and change.

Ceramics have often been used to explore social change and continuity in the past as they are well represented in the archeological record and can be associated to many different users and uses. However, as Rice (1984:234) explains, ceramics do not reliably and predictably accompany social change. This seems to be the case when regional pottery assemblages show important stylistic changes that do not correspond with shifts in other aspects of culture such as architecture or stone technologies, or when a certain kind of pottery remains stable during long spans of time although important political and economic changes occurred. In my opinion the perception of lack of direct association between material and social change may be the result of the nature of the studies that have been carried out. That is, most investigation on change in ceramics has only focused on final products, in other words, on the final visual appearance of artifacts. However, when the different steps of the process of manufacture of certain objects are considered (e.g., selection of raw materials, forming methods, morphology, decoration, etc.), another perspective emerges (see Gosselain 2000; Stark 1998; van der Leeuw 1993). As we will explore in this work, different dimensions of change and continuity can be detected; some of them correlate with certain aspects of social change while others do not. Also if the study of different phases of the biography of artifacts is extended to include distribution, use and disposal, different dimensions of change and continuity will also be detected. Therefore a study of material culture, in this case ceramics, designed to recognize patterns of change and continuity is more consistent when various steps of the process of manufacture are separately examined.

\section{A method to study change in material culture}

The idea that material culture contains various dimensions of change and continuity is not new. Erwin Panofski (1955) already claimed that in situations of cultural change, artistic forms may change, or meaning may change, but both do not necessarily change together. Material 
change, however, seems to be more complex as he suggested, as not only form and meaning change at different rates and scales, but also the form of artifacts has several components that change in variable ways. In this context, the study of technological change offers the possibility to get a better understanding of material change and its correlation to social change. A useful method is the analysis of the chaine opératoire. This term refers to a series of operations which brings a primary material from its natural state to a fabricated state (Cresswell 1976:6; Lemmonier 1986:149). The idea is that every operational step for producing an artifact involves various choices by the producer, which are relatively independent of previous or later choices. Thus, the finished product is the result of the various strategies followed by its producer, and the choices made at every stage of the process are the result of different circumstances and may be affected in different ways.

This method was first developed for Palaeolithic stone technologies, but recently it has been applied to analyze other technologies. Olivier Gosselain (2000) has made an excellent adaptation to explore social identities of potters. According to him, most technical options related to different stages of the manufacturing process of pottery are functionally equivalent; that is, they allow potters to achieve similar goals (Gosselain 2000:190). He suggests that the various steps of the sequence of pottery-making involve different processes of social interaction, reflecting various networks and strategies of the potters. Choices made at every step of the sequence are influenced by their degree of visibility in the community. Thus, each component of the chaîne opératoire has its own dynamic of change and continuity. For example, the method of forming vessels is generally very conservative as it involves motor skills and specialized gestures rooted in potters and is usually learned during childhood. This part of the process is normally not visible in finished pots, thus its selection should not be influenced by social pressure. In contrast, potters change more often their choices on clay selection, extraction, processing and firing. Gosselain argues (2000:192) that these stages reflect their interaction network. For example, a potter obtains clay from a particular source because it is in the property of relatives, or gains access to a certain kiln due to personal contacts. As a rule these production steps do not leave marks on the finished pots; for this reason, they can be easily modified without much influence of social pressure. In addition, potters make decisions about the vessel shape, surface finishing and decoration. These aspects are very visible on the pot, and openly show 
potters' behavior; therefore, they can be simply and often modified, and may reflect prevalent social preferences.

The method of forming pots is generally viewed as very conservative. For Sander van der Leeuw (1993:241, 256), the technique that craftsmen follow for forming is neither determined by the existent raw materials nor by tools, but rather by the conceptualization that artisans have of their own pottery technology. That is, what potters consider as essential characteristics of their pots, and how they think pots should be done. For van der Leeuw (1993:257) the idea that potters have about their technology is composed of three fundamental aspects: (a) the topology, which the potter brings to bear on his dealing with shapes, for example, if potters see their pots as horizontal, vertical or as a transformation of a sphere; (b) the partonomy, which the potter applies to the shape, for example, what are considered the basic entities of which the pot is made such as a number of coils, or two or more pot segments, and (c) the sequence in which the vessel is made, for example, from bottom to top or vice versa. Thus topology, partonomy and sequence are fundamental elements of any pottery tradition since, according to van der Leeuw (1993:259), they underlie the ways in which a particular culture deals with the problems which it encounters in the material world. He believes that these three aspects are resistant to change because they permeate very large areas of activity of a group of people, they are shared, and people are largely unaware of their existence. Thus, the method of forming tends to be resistant to new ideas, technologies and consumers.

The sum of the choices that a potter makes in every step of the sequence of manufacturing results in the style of a pot. In my opinion style should embrace far more than the decoration of objects. It should include the preferences for certain raw materials, manufacturing methods, firing, etc., as Wobst (1999) suggested. If style is viewed only as the decorative part of an artifact it has the risk of being reduced to aesthetic taste. For this reason, Heather Lechtman (1977:4) introduced the concept of technological style to refer to the style of the process of manufacture. However, a distinction between 'style' and 'technological style' is difficult to establish as the difference between ornamental and functional features of an artifact is ambiguous and culturally determined. In addition, all the choices that potters make from a variety of possibilities during the process of manufacturing are active efforts, even when potters decide to conserve, without change, 
earlier methods or elements or when choices are limited by habits, social pressure or environmental restrictions.

\section{Conservatism of potters}

It is paradoxical that archeologists often use ceramics to explore social change while at the same time it is generally assumed that potters are traditionalist and conservative. An early promoter of the idea that potters are conservative was George Foster, an authority of pottery studies in Mesoamerica. For him present-day potters from Tzintzuntzan in western Mexico were evidently conservative (Foster 1967). Although he found that in that town some potters were innovators, he observed that they were relative newcomers who had lived there only for one or two generations. He supposed that they were not acquainted with the norms of the community, and therefore were not restricted by them (Foster 1967:293-310). In his opinion, the conservatism of potters was inherent to a production process that encouraged caution. Also May Díaz $(1966: 17,138)$ in her study of contemporary pottery from Tonalá, found that potters resisted technical innovation, even when there were economic and market stimuli. She believed that potters made any clay object which could be made by the molding methods they were accustomed to and by using their usual type of kiln, but nothing more. Thus, new pottery types could be made to satisfy demand, but the technology of production remained stable. She argued that the reason for this conservatism was that pottery was produced in family workshops in which the strong influence of the family head and a three-generation structure of knowledge transmission favored traditionalism.

There have been, however, other studies that do not support such conservatism. In the same manner as Foster and Díaz, several researchers have registered in detail potters' life and technology, but have found lively dynamics of change. It is remarkable that studies supporting potters' conservatism in Mexico were done in the 1960s. In contrast, research done in the 1970s and later suggests that such conservatism was only associated to a few parts of the production process while other parts were marked by creativity and innovation. Roberta Katz (1977), for example, done after Díaz another study of the pottery of Tonalá but she found a different situation. She observed that since 1959 the greatly increased demand for Tonalá ware in 
diverse Mexican markets motivated potters to seek means for making their production more efficient. As a result, pottery technology in the town changed in several phases of the manufacturing process. In particular, potters acquired ready-ground clay, preferred vertical-halves molds to mushroom molds, and were building bigger and stronger kilns than before (Katz 1977:164).

Beate Engelbrecht (1987) found a similar situation among the potters from Patamban and Tzintzuntzan in West Mexico. She observed that potters experimented with new techniques to adapt to the changing market needs, without strongly changing the style of their pottery. She saw that the variation in vessel shapes and decoration increased a lot in the 1970s and 1980s because consumers from the city increased. She recognized, however, that old manufacturing techniques were conserved. Thus she concluded that pottery was a craft characterized by flexibility and adaptation capacity (Engelbrecht 1987:195, 364). From 1965 to 1997 Dean Arnold studied the manufacture of pottery in Ticul, Yucatan, and he arrived at similar results. During his longterm study he observed that changes in pottery distribution, vessel shape and decoration were relatively quick whereas clay sources and composition and technology of production changed more slowly (Arnold 2008:313-326). He believes that potters were able to adapt to social changes in Yucatan, such as modernization and the enormous development of the tourism industry, because they have a diversity of fabrication techniques, decoration, clay recipes and vessel shapes. They, however, maintained part of their traditional techniques because pottery production is household-based and knowledge transmission is kin-based. According to Arnold (2008:313) the diversity of fabrication techniques has been one of the main reasons for the survival of ceramic-making in that town, as potters can choose the most convenient techniques to adapt to changing demand. In my opinion, however, this does not mean that potters may use indistinctly several fabrication techniques. Rather, as his accounts suggest, potters know several manufacturing techniques as is the case of many potters in Mexico, but they maintain the same technique to produce the same kind of pots.

Also Dick Papousek $(1981,1984)$ studied three pottery-making towns in the State of Mexico-San Juanico, Santa María Canchesdá and Santiago Coachochitlán-and found that from the 1950s till the 1980s important changes in pottery-making were occurring. He observed that those changes concerned the production process rather 
than the production methods, the distribution rather than the production, as well as the quantity rather than the quality of the products (Papousek 1981:52). Besides, he recognized that during the 1970s there was rapid modernization in pottery production, although he also acknowledged that there were some conservative potters (Papousek 1981:129-131, 1984:478). For him, the desire to change in these towns arose from previous necessity. This necessity was motivated by internal demographic pressure and by ecological problems, in particular, scarcity of firewood. Louana Lackey (1981) observed as well an impulse of innovation and change in the pottery town of Acatlán between 1974 and 1977. After the decline in demand for traditional wares, potters decided to create new kinds of vessels and designs for tourists, although the methods of manufacture remained the same. They increased the variety of their products, gave special attention to artistic and imaginative vessels, and as the roads and means of communication were improved in the region, they could sell their products in many other places. Thus by concentrating on a new type of market, tourism, the ceramic industry acquired a new impetus.

In a similar manner, Keith Nicklin (1971), after an exhaustive review of the literature on pottery technology worldwide, concluded that pottery-making was not inherently conservative. Stability in raw materials, techniques and forms are provoked by static economic and social conditions. Changes in these conditions often give rise to changes in such aspects of pottery manufacture. Therefore, it is possible that the potters' apparent conservatism found by researchers prior to the 1970s in Mexico was associated to the general static situation of the peasant society at that time. During the 1970s, in contrast, a wide and generalized modernization trend began in Mexico related to high population growth, industrialization and mobility from rural to urban centers. Also traditional crafts such as pottery were stimulated by national programs of development. Likely this trend also had effects on potters' lives and their manufacturing technologies in different regions of the country. We will explore this later in more detail.

Thus, it seems that potters in general are conservative in certain aspects of the manufacturing process but innovative in others. The conservative reproduction of culture as well as innovation and experimentation are usually related to the existing social conditions. In addition, every pottery community has a particular historical and social context, and for this reason, generalizations on the direction of pottery change and its relation to social change cannot be made. 
Furthermore, in Mexico potters are usually peasants. They combine pottery-making with agricultural work, and for this reason their way of life is similar to that of millions of Mexican peasants. That is, potters' access to resources and to social welfare such as medical services, school and social security, has been similar and has followed similar trends to that of peasants. In the last three decades, however, in several towns close to urban centers pottery-making has become a specialized industry, as we will explore later. Families of potters have dedicated themselves completely to pottery manufacturing, and therefore, parts of the process of ceramic-making have been altered, and their way of life has to some extent been distanced from that of peasants.

\section{Change and continuity in pottery-making}

As this study involves analysis of the processes of change and continuity in ceramics during a long span of time, it requires considering archeological ceramic remains as well as present-day ceramics. As commented above, change and continuity can be more adequately understood when several stages of the manufacturing sequence are studied rather than focusing only on vessel shape and decoration, as has often been the case. This is feasible in the case of present-day ceramics; however, archeological remains offer often only fragmentary insights on some of the manufacturing steps. Many aspects of ancient processes of manufacture cannot be reconstructed; however, detailed low-tech observation permits us to gain important insights. For example, archeological ceramic fragments can provide information on clay selection and preparation, forming method, firing, shape, surface finishing and decoration. Technological methods of observation such as petrography or neutron activation analysis help to refine macroscopic observation; for example, they are particularly useful to identify clay provenance, as they permit us to identify in detail the mineralogical and the chemical composition of ceramics. These methods, however, do not help us to recognize many other aspects of the process of manufacture as normally the first steps of production are covered by later steps, and different procedures may leave similar marks on pottery.

Observation of sherds permits us to identify to some extent clay recipes used by potters, and if inclusions were added to improve clay 
quality or if in a particular community recipes were standardized. Observation also permits us to recognize the method of forming vessels. Typical forming techniques in pre-Hispanic and contemporary Mesoamerica are: (a) molding, that is pressing plastic clay into or over a mold which is made from clay and fired or from gypsum for durability; (b) coiling, that is building up a vessel with rolls or coils of clay of uniform thickness, and (c) pinching, that is squeezing clay between the fingers in order to build up walls (Rye 1981:67-81). Frequently vessels are formed by a combination of these methods. Marks on the vessel surface permit us to recognize to some extent the forming methods, as well as the type and quantity of molds used and the sequence of forming. In addition, observation permits us to obtain a few data on firing techniques. For example, pots fired in an oxidizing atmosphere, that is, with excess of oxygen, have an orange color; while pots fired in a reduced atmosphere, that is, with excess of carbon monoxide as a result of insufficient air during firing, have a gray color (Rye 1981:96). Also firing clouds on the vessel surface give some indication if open firing or a kiln was used and if firing was carefully controlled or not. Observation of sherds also permits us to reconstruct the shape and size of the vessel, and if form and size standardization were important in a pottery community. Furthermore observation permits us to recognize to some extent the methods of surface finishing, for example, if vessels were smoothed, polished or burnished, or if a glaze coating was applied. The methods and motifs of decoration can be reconstructed when fragments are big enough to give an impression of the vessel's decorative plan.

Studies of archeological ceramics have usually focused on the morphology and decoration of vessels. These aspects of the process of manufacturing easily change and openly reflect potters' preferences and social pressure. Therefore they permit us to recognize material change, in particular shifts in vessels' appearance and trends of decoration. This focus, however, does not help to give a wide perspective on change and continuity, as it does not consider those aspects of ceramic-making resistant to change or with a slow rate of modification such as the forming methods. An integral study of several steps of the process of manufacturing offers insights on the dynamics of change, but also on the dynamics of continuity. 


\section{Summary}

In the social sciences there have been several perspectives on the relationship between material culture and social change. In this study the view is preferred in which objects are not only considered a reflection of social life but also active constituents of it. This is particularly evident in colonial situations as many pre-colonial objects acquire different roles in the new colonial society and are able to motivate certain social relations. For example, simple indigenous objects that in precolonial times in Mesoamerica were commodities may be turned into valuables in the colonial society, and in that way they could motivate in producers and users a variety of new responses. Change in material culture, however, does not correlate directly to social change. Material culture has various dimensions of change, and they are related in complex ways to social change. In addition, change and continuity are not polar oppositions but intrinsically complementary. A means that permits us to recognize different aspects of change and continuity of material culture, in this case ceramics, is the study of the several stages of the process of manufacturing. Examples from many parts of the world show that parts of the process of manufacture are very conservative, such as the forming technique, while others easily change such as decoration. When the whole process is studied in detail the supposed conservatism of potters cannot be supported; craftspeople are traditionalists in some aspects but creative and innovative in many others. 